\title{
Epidemiology of Mild Cognitive Impairment in Brazil
}

\author{
Sonia Maria Dozzi Brucki ${ }^{1}$
}

\begin{abstract}
With the worldwide increase in longevity and rising prevalence of cognitive disorders in the aged population, efforts have been made to characterize mild cognitive impairment $(\mathrm{MCl})$ and its prevalence and/or incidence in a number of countries, given $\mathrm{MCl}$ may be a pre-dementia phase of degenerative conditions. The aim of this review was to retrieve the available data on the prevalence and incidence of mild cognitive impairment (MCl) in Brazil and compare these with rates found by studies conducted in other countries. The Pubmed and Scielo databases were searched using the following search terms: mild cognitive impairment, prevalence, incidence, including studies in both English and Portuguese languages. Only one study on $\mathrm{MCl}$ prevalence has been published in Brazil, reporting a prevalence rate of $6.1 \%$ and incidence of 13.2/1000 persons-year among those aged 60 years or over. Prevalence rates for other countries are also reported. The prevalence and incidence of $\mathrm{MCl}$ found in Brazil is similar to rates observed in other countries.
\end{abstract}

Key words: mild cognitive impairment, epidemiology, prevalence, incidence, Brazil

\section{EPIDEMIOLOGIA DO COMPROMETIMENTO COGNITIVO LEVE NO BRASIL}

RESUMO. Com o aumento da longevidade mundial e o crescimento da prevalência de distúrbios cognitivos nesta população, tem-se tentado caracterizar o comprometimento cognitivo leve e sua prevalência e/ou incidência nos diversos países. Uma vez que, este quadro pode ser uma fase pré-demencial dos quadros degenerativos. Esta revisão tentou recolher os dados disponíveis quanto a prevalência e incidência de comprometimento cognitivo leve (CCL) no Brasil e comparar em relação aos demais estudos em outros países. Foram revistas as bases PubMed e Scielo com os termos: comprometimento cognitivo leve, prevalência, incidência, foram incluídos estudos em inglês, português. Apenas um estudo de prevalência de CCL foi publicado no Brasil, com taxa de 6,1\% e incidência de 13,2/1000 pessoas-ano entre aqueles de 60 anos ou mais. São mostradas as taxas nos demais países. A prevalência e incidência de CCL no Brasil encontram-se dentro das faixas observadas entre outros países.

Palavras-chave: comprometimento cognitivo leve, epidemiologia, prevalência, incidência, Brasil

\section{INTRODUCTION}

$\mathrm{T}$ he aging of the world population has been extensive and constantly disseminated by surveys and media channels. The importance of this phenomenon centers largely on the burden that it places on the world. Concomitant with aging, besides retirement from work and the costs of pension payments, are the disease most commonly associated with aging, including dementia, amongst others. Many countries have attempted to improve control of age-related chronic non-communicable diseases, which are associated with increased morbimortality.

According to data from the World Health
Organization (WHO), between 2000 and 2050 , the proportion of the world population over 60 years of age is set to double from $11 \%$ to $22 \%$ (605 million to over two billion). An estimated $80 \%$ of elderly in the world will reside in low and medium-income countries, placing a heavy burden on the governments of these countries. Life expectancy in Brazil has risen from 67 years in 1990 to 73 years in 2009 . The population aged 65 years or older has grown in recent decades; at the last census in 2010, this group represented $7.4 \%$ of the population but exhibited a heterogeneous distribution by region (ranging from 4.6 in the Northern region to $8.1 \%$ in the South and Southeast).

'MD, PhD. Cognitive Neurology and Behavioural Group. FMUSP. São Paulo SP, Brazil.

Sonia Maria Dozzi Brucki. Rua Rio Grande 180/61 - 04018-000 São Paulo SP - Brasil. E-mail: sbrucki@uol.com.br

Disclosure: The authors report no conflicts of interest.

Received June 03, 2013. Accepted in final form August 10, 2013. 
More recently, attention has been focused on milder cognitive disorders. The concept of mild cognitive impairment has been used in population-based studies in recent years.

The concept of Mild Cognitive Impairment (MCI) emerged to classify individuals who are at an intermediate stage between normal cognition and dementia, more specifically AD. ${ }^{1}$

Initially, the diagnostic criteria of $\mathrm{MCI}$ emphasized memory impairment and defined a risk factor for progression to $\mathrm{AD}$. MCI was later recognized as a heterogeneous entity in terms of its clinical presentation, etiology and prognosis, whereby deficits in other cognitive domains, besides memory, became accepted with the resultant division of $\mathrm{MCI}$ into subtypes. Thus, four subtypes have been defined: amnestic MCI single domain, amnestic MCI multiple domains, nonamnestic MCI single domain, and nonamnestic MCI multiple domains. ${ }^{2}$

This objective of this review was to retrieve the available data on the prevalence and incidence of $\mathrm{MCI}$ in Brazil and compare these with rates found by studies conducted in other countries.

\section{METHODS}

Literature searches were performed on PubMed and Scielo databases using the search terms "mild cognitive impairment", "epidemiology", "prevalence", and "incidence" for studies published between 1994 and September 2013. We searched the reference lists of retrieved papers to identify additional articles. Only fulltext papers written in English, Portuguese, Spanish, and French were considered.

Prevalence. The estimated prevalence of $\mathrm{MCI}$ among elderly over 70 years of age is 14 to $18 \%{ }^{3}$ This prevalence can vary depending on the criteria adopted, types of tests employed and their cut-off values, as well as the age and educational level of the population under study. In a recent meta-analysis, prevalence ranged from $3 \%$ to $42 \%{ }^{4}$

In community-based studies, the prevalence of amnestic MCI ranged from $2.1 \%$ to $11.5 \% .{ }^{5} \mathrm{~A}$ Korean study using Peterson's criteria found a prevalence of $28.6 \%$, ${ }^{6}$ whereas a Mexican study using the same criteria but different instruments reported a prevalence of $6.45 \% .{ }^{7} \mathrm{An}$ intermediate rate was observed in a study conducted in Germany, with a prevalence of $7.8 \%$ using the original criteria and $12.1 \%$ when cognitive impairment complaints were excluded. ${ }^{8}$ In a meta-analysis of Chinese studies, MCI prevalence in the elderly population was $12.7 \%$ with a higher rate among illiterates. ${ }^{9}$ The prevalence in Italy was $6.0 \%$, with the most frequent type being nonamnestic MCI single domain. ${ }^{10}$ In a rural area of Japan, MCI prevalence was high (23.5\%), while the most frequent type was nonamnestic. ${ }^{11}$

In the population-based 10/66 study, the prevalence of amnestic MCI was between $0.8 \%$ in China and $4.3 \%$ in India (the study included low and middle-income countries). A total of 15376 participants were assessed, where scores 1.5 standard deviations below age- and schooling-adjusted means were considered abnormal memory performance. ${ }^{5}$

The prevalence of $\mathrm{MCI}$ in Medellin (Colombia) was $9.7 \%{ }^{12}$

The analysis of the literature available yielded only one study on MCI in Brazil, published by Godinho et al. ${ }^{13}$ based on data from the city of Porto Alegre (in the Southern region of Brazil). The study found a prevalence of MCI of $6.1 \%$ ( $n=21), 24 \%$ remained stable while $38 \%$ improved during follow-up treatment; the annual rate of conversion from $\mathrm{MCI}$ to $\mathrm{AD}$ was $8.5 \%$.

Some authors of epidemiological studies have adopted the cognitive impairment no dementia (CIND) criteria, in which the individual has cognitive impairment yet without loss of functioning, not requiring confirmation by a companion or long-term follow-up.

In Brazil, surveys have been grounded in the concept of cognitive and functional impairment (which encompasses cognitive impairment, dementia and functional loss of all causes).$^{14}$

Preliminary data from the study by César et al. (2013) revealed a CIND prevalence in the city of Tremembe (hinterland of São Paulo State - Southeastern region) of $18.6 \% .^{15}$

In the population-based PIETA study in elderly aged 75 or over, the prevalence of CIND was $25.2 \%$ and associated factors were advanced age, low socioeconomic level, depression and history of thyroid dysfunction. ${ }^{16}$

In a riverside-dwelling population with low schooling and practically no vascular risk factors, CIND prevalence was $7.7 \%$. Unlike the other studies cited, this investigation was conducted in a rural zone among individuals aged 50 or older. ${ }^{17}$

In the United States, the prevalence of CIND in those over 70 years of age was $22.2 \%$, ranging from $16 \%$ (71 to 79 years) to $39 \%$ ( $\geq 90$ years). ${ }^{18}$

In the United States and Canada, prevalence ranged from 17 to $23 \%$ whereas in Europe the rate ranged from 21 to $27 \%$. In published reviews, rates ranged from 5 to $29 \% .{ }^{19-26}$ The average prevalence among Afro-Americans was $23.4 \%$ (rising with age, from $19.2 \%$ to $38 \%$ ). ${ }^{26}$

In the city of Guadalajara in Mexico, the prevalence was $13.8 \%$ in a sample whose educational level varied 
widely from zero to 23 years of schooling and averaging 4.4 years, where $23 \%$ had no formal education. The factors associated with cognitive impairment were low schooling, age over 75 years, being unmarried, and depression. The greatest risk factor was educational level (OR=9.06); with a prevalence of $21 \%$ among those with zero to four years of schooling. ${ }^{27}$

In Taiwan, a prevalence of $9.7 \%$ was found among 6192 elderly subjects (aged over 65 years), with schooling exerting a major influence. ${ }^{28}$

In an Italian study conducted in Florence, CIND incidence was 21.37/1000 persons-year ${ }^{18}$ (DiCarlo et al., 2007).

Incidence. Incidence studies are generally harder to perform since they require greater time and resources (both financial and human) to conduct. Consequently, fewer incidence studies are available compared to prevalence studies, which represent a snapshot of a particular moment in time. Prevalence is the result of incidence (the development of new cases of a given disease) and survival time with the disease. If a disease has less evolution and greater mortality, it will have a lower prevalence in the population. Incidence studies are better for assessing the actual situation of the population regarding the disease.

The annual incidence of $\mathrm{MCI}$ is around $5 \%$ in individuals over 65 years of age. ${ }^{29}$ The incidence of amnestic MCI ranges from 9.9 to $40.6 / 1000$ persons-year and of nonamnestic forms from 28 to $36.3 / 1000$ persons-year. According to the systematic review by Luck et al. (2010), the incidence for all forms of $\mathrm{MCI}$ ranged from 51 to $76.8 / 1000$ persons-year, where the main risk factors for conversion were age, low schooling, and arterial hypertension..$^{30}$ In a more recent systematic review, an incidence of 21.5-71.3/1000 persons-year was identified for MCI and 8.5-25.9/1000 persons-year for amnestic MCI. ${ }^{4}$

In a population-based cohort study following around 2000 individuals for up to four years, approximately $30 \%$ of the participants developed MCI. ${ }^{31}$

The only study in Brazil including $\mathrm{MCI}$ incidence data showed a rate of 13.2/1000 persons-year among those aged 60 years or over, after an 8-year follow-up. Risk factors detected were educational level and initial scores on the Min-Mental State Exam (MMSE), with age not proving significant. ${ }^{32}$

\section{DISCUSSION}

In general, $\mathrm{MCI}$ and CIND are more frequent than dementia, since the majority of individuals are at a preclinical stage with greater risk of conversion to dementia, whereas others never convert to dementia constituting a larger number of individuals in this state. The number is higher owing to the fact that this condition can persist for many years, with no clearly defined ratio for conversion to dementia. This impairment may be attributable to other non-degenerative causes such as those which are vasculatures, secondary to systemic diseases, metabolic and deficiency-induced; or even secondary to psychiatric conditions such as depression. Therefore, its frequency may be greater and fluctuate over time. The concept seems more suitable for use in epidemiological studies because it does not require confirmation of cognitive decline over time or confirmation by the companion, as suggested for diagnosing mild cognitive impairment. Therefore, it represents a more accurate concept for cross-sectional studies with less likelihood of bias.

We noted that the prevalence of $\mathrm{MCI}$ in our milieu lies midway between the rates of other countries for the over 60 age group. In studies assessing older populations, rates were found to be higher. Taking CIND into consideration gave a rate of between $7.7 \%$ and $25.2 \%$. The studies retrieved differed in terms of risk factors involved, research setting, and chiefly in the age of subjects assessed. The prevalence in Brazil is similar to rates found for other populations.

Reanalyzing the incidence data, only the study involving a sample from the city of Porto Alegre provides this information, whose incidence was found to be lower than rates reported in a recent systemic review (Ward).

In conclusion, further studies of the Brazilian population are needed, controlling differently for risk factors, diet, educational levels, genetic background, among others. Studies of prevalence and incidence should be carried out in a continuous and repeated manner throughout the year, since today's risk factors may not be the same as those of tomorrow.

\section{REFERENCES}

1. Petersen RC, Smith GE, Waring SC, Ivnik RJ, Tangalos EG, Kokmen E. Mild cognitive impairment: clinical characterization and outcome. Arch Neurol 1999;56:303-308.

2. Petersen, RC. Mild cognitive impairment as a diagnostic entity. J Intern Med 2004;256:183-194.

3. Luck T, Riedel-Heller SG, Kaduszkiewicz H, et al. Mild cognitive impair- ment in general practice: age-specific prevalence and correlate results from the German study on ageing, cognition and dementia in primary care patients (AgeCoDe). Dement Geriatr Cogn Disord 2007;24:307-316.

4. Ward A, Arrighi HM, Michels S, Cedarbaum JM. Mild Cognitive impairment: disparity of incidence and prevalence estimates. Alzheimer's Dement 2012;8:14-21. 
5. Sosa AL, Albanese E, Stephan BCM, et al. Prevalence, distribution, and impact of mild cognitive impairment in Latin America, China, and India : a 10/66 population-based study. Plos Med 2012;9:e1001170.

6. Lee SB, Kim KW, Youn JC, et al. Prevalence of Mild Cognitive Impairment and Its Subtypes Are Influenced by the Application of Diagnostic Criteria: Results from the Korean Longitudinal Study on Health and Aging (KLoSHA). Dement Geriatr Cogn Disord 2009;28:23-29.

7. Juarez-Cedillo T, Sanchez-Arena R, Sanchez-Garcia S, et al. Prevalence of Mild Cognitive Impairment and Its Subtypes in the Mexican Population. Dement Geriatr Cogn Disord 2012;34:271-281.

8. Dlugaj M, Weimar C, Wege N, et al. Prevalence of Mild Cognitive Impairment and Its Subtypes in the Heinz Nixdorf Recall Study Cohort. Dement Geriatr Cogn Disord 2010;30:362-373.

9. Nie H, Xu Y, Liu B, et al. The prevalence of mild cognitive impairment about elderly population in China: a meta-analysis. Int $\mathrm{J}$ Geriatr Psychiatry $2011 ; 26: 558-563$.

10. Moretti F, De Ronchi D, Palmer K, et al. Prevalence and characteristics of mild cognitive impairment in the general population. Data from an Italian population-based-study: The Faenza Project. Aging Ment Health 2013;17:267-275.

11. Wada-Isoe K, Uemura $Y$, Nakashita S, et al. Prevalence of Dementia and Mild Cognitive Impairment in the Rural Island Town of Ama-cho, Japan. Dement Geriatr Cogn Dis Extra 2012;2:190-199.

12. Henao-Arboleda E, Aguirre-Acevedo DC, Muñoz C, Pineda DA, Lopera F. Prevalence of mild cognitive impairment, amnestic-type, in a Colombian population. Rev Neurol 2008;46:709-713.

13. Godinho C, Camozzato AL, Onyszko D, Chaves ML. Estimation of the risk of conversion of mild cognitive impairment of Alzheimer type to Alzheimer's disease in a south Brazilian population-based elderly cohort: the PALA study. Int Psychogeriatr. 2012;24:674-681.

14. Lopes MA, Ferrioli E, Nakano EY, Litvoc J, Bottino CM. High prevalence of dementia in a community-based survey of older people from Brazil: association with intellectual activity rather than education. J Alzheimers Dis 2012;32:307-316.

15. César KG, Brucki SMD, Nitrini R. Prevalence study of cognitive impairment with and without dementia in Tremembé, São Paulo - Preliminary results. Dement Neuropsychol 2013;7(Suppl 1):10.

16. Caramelli $P$, Barbosa MT, Beato RG, et al. Variables associated with cognitive impairment and dementia in a low-educated cohort aged 75+ years: The PIETÀ study. Dement Neuropsychol 2013;7(Suppl 1):15-16.

17. Brucki SMD. Avaliação cognitiva e diagnóstico de comprometimento cognitivo em indivíduos de baixa escolaridade. Tese de Livre-Docência em Neurologia. Faculdade de Medicina da Universidade de São Paulo.

18. Plassman BL, Langa KM, Fisher GG, et al. Prevalence of dementia in the United States: the aging, demographics, and memory study. Neuroepidemiology 2007;29:125-132.
19. Di Carlo A, Lamassa M, Baldereschi M, et al. CIND and $\mathrm{MCl}$ in the Italian elderly: frequency, vascular risk factors, progression to dementia. Neurology 2007;68:1909-1916.

20. Gauthier S, Reisberg B, Zaudig M, et al. International Psychogeriatric Association Expert Conference on Mild Cognitive Impairment. Mild cognitive impairment. Lancet 2006;367:1262-1270.

21. Graham JE, Rockwood K, Beattie BL, et al. Prevalence and severity of cognitive impairment with and without dementia in an elderly population. Lancet 1997;349:793-796.

22. Hanninen T, Koivisto K, Reinikainen KJ, et al. Prevalence of ageingassociated cognitive decline in an elderly population. Age Ageing 1996; 25:201-205

23. Lopez OL, Jagust WJ, DeKosky ST, et al. Prevalence and classification of mild cognitive impairment in the Cardiovascular Health Study Cognition Study: part 1. Arch Neurol 2003;60:1385-1389.

24. Ritchie K. Mild cognitive impairment: an epidemiological perspective. Dialogues Clin Neurosci 2004;6:401-408.

25. Ritchie K, Artero S, Touchon J. Classification criteria for mild cognitive impairment: a population-based validation study. Neurology 2001; 56:37-42.

26. Unverzagt FW, Gao S, Baiyewu O, et al. Prevalence of cognitive impairment: data from the Indianapolis Study of Health and Aging. Neurology 2001;57:1655-1662.

27. Ortiz GG, Arias-Merino ED, Flores-Saiffe ME, Velázquez-Brizuela IE, Macías-Islas MA, Pacheco-Moisés FP. Prevalence of Cognitive Impairment and Depression among a Population Aged over 60 Years in the Metropolitan Area of Guadalajara, Mexico. Curr Gerontol Geriatr Res 2012;2012:175019.

28. Fei M, Qu YC, Wang T, Yin J, Bai JX, Ding QH. Prevalence and distribution of cognitive impairment no dementia (CIND) among the aged population and the analysis of socio-demographic characteristics: the community-based cross-sectional study. Alzheimer Dis Assoc Disord 2009;23:130-138.

29. Manly JJ. Tang MX, Schupf N, Stern Y, Vonsattel JP, Mayeux R. Frequency and course of mild cognitive impairment in multiethnic community. Ann Neurol 2008;63:494-506.

30. Luck T, Luppa M, Briel S, Riedel-Heller SG. Incidence of mild cognitive impairment: a systematic review. Dement Geriatr Cogn Disord 2010; 29:164-175.

31. Ganguli M, Fu B, Chang J. Vascular risk-factors for development of mild cognitive impairment at the populational level. Oral presentation. Brain aging and dementia in developing countries, Nairobi, Kenya, 4-7 dec, 2012.

32. Chaves ML, Camozzato AL, Godinho C, Piazenski I, Kaye J. Incidence of mild cognitive impairment and Alzheimer disease in Southern Brazil. J Geriatr Psychiatry Neurol 2009;22:181-187. 